\title{
Postcataract endophthalmitis prophylaxis using irrigation, incision hydration, and eye pressurization with vancomycin
}

This article was published in the following Dove Press journal:

Clinical Ophthalmology

17 July 2015

Number of times this article has been viewed

\author{
Lee P Schelonka' \\ Margaret A SaBell ${ }^{2}$ \\ 'Department of Opthalmology, Kaiser \\ Permanente Lone Tree Medical \\ Offices, Lone Tree, ${ }^{2}$ Department \\ of Infection Control, Kaiser \\ Permanente Lone Tree Medical \\ Offices, Lone Tree, Denver, CO, USA
}

Correspondence: Lee P Schelonka Department of Opthalmology, Kaiser Permanente Lone Tree Medical Offices, 10240 Park Meadows Drive, Lone Tree, Denver, CO 80124, USA

Tel + I 303649543 I

Fax + I 3036495405

Email leeschelonka@msn.com
Purpose: This study aimed to determine whether switching from balanced salt solution (BSS) to vancomycin $20 \mathrm{~g} / \mathrm{mL}$ BSS for incision hydration and eye pressurization reduces the rate of postcataract endophthalmitis.

Methods: This was a patient safety/quality improvement project, including all patients undergoing cataract surgery at the Kaiser Permanente Colorado Ophthalmology Department from January 2002 to December 2014. Throughout the study, patients received vancomycin $20 \mu \mathrm{g} /$ $\mathrm{mL}$ in the irrigating solution. During the baseline period from 2002 to 2005, surgeons pressurized eyes and hydrated incisions with plain BSS. During the intervention period from 2006 through 2014, surgeons switched from BSS to the vancomycin/BSS irrigating solution for eye pressurization and incision hydration.

Results: A total of 57,263 cataract operations were performed by 24 surgeons at seven surgical centers: 12,400 in the baseline period and 44,863 in the intervention period. The rate of postcataract endophthalmitis declined significantly from 5/12,400 (rate: $0.4 / 1,000$ ) in the baseline period to $1 / 44,863$ (rate: $0.022 / 1,000$ ) during the intervention period (odds ratio [OR]: 18.1, 95\% confidence interval $\left.[\mathrm{CI}]: 2.11-154.9 ; \chi^{2}=13.5, P=0.00024\right)$. Accounting for an estimated 2.05fold risk reduction due to confounding variables, the risk reduction attributed to the intervention remained significant: (adjusted OR: $8.78,95 \%$ CI: $1.73-44.5 ; \chi^{2}=10.06, P=0.0015$ ). Since 2009, we have not experienced any cases of postcataract endophthalmitis after 32,753 operations.

Conclusion: We experienced a significant reduction in postcataract endophthalmitis when we switched from BSS to the vancomycin/BSS irrigating solution for incision hydration and eye pressurization. The pharmacokinetics profile indicates that this switch was important for effective prophylaxis.

Keywords: endophthalmitis, cataract surgery, vancomycin irrigation, quality improvement

\section{Introduction}

Postcataract endophthalmitis is an uncommon, potentially devastating complication of cataract surgery. In the Endophthalmitis Vitrectomy Study, 31\% of patients had visual acuity 20/200 or worse at 3 months after diagnosis. ${ }^{1}$ The most recently reported rate of postcataract endophthalmitis among US Medicare members was 1.11/1,000 in 2004. ${ }^{2}$ Because US surgeons operate approximately 3.5 million cataract cases annually, ${ }^{3,4}$ there are approximately 3,885 endophthalmitis cases, causing severe, permanent iatrogenic vision loss in approximately 1,200 eyes each year. Internationally, the rate is as much as ten times higher. ${ }^{5}$

Risk factors for endophthalmitis include age $>85$ years, ${ }^{2}$ posterior capsule rupture,${ }^{6}$ clear corneal incisions (particularly when they leak on postoperative day 1), ${ }^{6,7}$ the use of silicone (rather than acrylic or polymethyl methacrylate) intraocular lenses 
(IOLs), ${ }^{6}$ low surgeon caseload, ${ }^{2}$ the failure to use povidoneiodine on the ocular surface, in addition to the povidoneiodine skin preparation, ${ }^{8}$ and the failure to use intracameral antibiotics. ${ }^{6,9-12}$ This study addresses the questions of safety and efficacy of vancomycin irrigation for endophthalmitis prophylaxis, while accounting for the confounders of declining intraoperative complication rates, declining silicone IOL use, and increasing surgeon caseloads in Kaiser Permanente Colorado Ophthalmology Department.

Vancomycin is the most widely used intracameral antibiotic in the US. ${ }^{13}$ According to the 2012 Annual Survey of United States members of the American Society of Cataract and Refractive Surgery, approximately $50 \%$ of cataract cases were operated using intracameral antibiotics, evenly split between irrigation and injection. ${ }^{13}$ In these cases, $56 \%$ of surgeons used vancomycin (approximately 980,000 cases, assuming the survey results can be extrapolated nationwide), while 31\% used moxifloxacin and 13\% used cefuroxime. ${ }^{13}$ Although cefuroxime has been packaged and approved for intracameral use in Europe (Aprokam, Thea, Clermont-Ferrand, France), no intracameral antibiotic has been packaged or approved in the US.

Since 2002, every cataract patient in the Kaiser Permanente Colorado Ophthalmology Department has received vancomycin $20 \mu \mathrm{g} / \mathrm{mL}$ in the irrigation fluid. ${ }^{14}$ When we diagnosed four cases of postcataract endophthalmitis in 2005, we reevaluated our protocols, with particular attention to the pharmacokinetics of vancomycin prophylaxis.

\section{Pharmacokinetics}

Contamination of the anterior chamber is common after cataract surgery, although the colony counts are low (20-60 colony forming units $[\mathrm{CFU}] / \mathrm{mL}) .{ }^{15}$ The most common postcataract endophthalmitis pathogen is coagulase-negative Staphylococcus. ${ }^{16,17}$ Vancomycin's mean inhibitory concentration for $90 \%$ of Staphylococcus endophthalmitis pathogens $\left(\mathrm{MIC}_{90}\right)$ was 3-4 $\mu \mathrm{g} / \mathrm{mL}$ in two recent series. ${ }^{18,19}$ Vancomycin is a slow killer, requiring 4.6 hours to reduce Staphylococcus epidermidis colony counts by a factor of 100 under ideal growth conditions. ${ }^{20}$ Mutant, highly resistant, slime-forming Staphylococcus epidermidis has a 1-hour delay in killing, while vancomycin dislodges the bacteria from the lens implant, particularly from a silicone lens implant. ${ }^{21}$ This may partially explain the increased risk of endophthalmitis with silicone lens implants. ${ }^{6}$ It is not surprising that vancomycin failed to sterilize aqueous in experiments lasting up to 120 minutes: ${ }^{15,22-24}$ the contact time was shorter than vancomycin's known kill time..$^{20,21,25}$
If surgeons hydrate the incisions and pressurize eyes with the irrigating solution, the vancomycin concentration at the end of surgery is $20 \mu \mathrm{g} / \mathrm{mL}$. After surgery, the vancomycin concentration drops through two-step kinetics: the half-life is 1.80 hours to 1.87 hours in the first 2 hours, ${ }^{15,22}$ then dilution slows, with a half-life of 3.27 hours for the next 16 hours. $^{26}$ On the basis of these measurements, it takes approximately 6.45 hours for the vancomycin concentration to drop from $20 \mu \mathrm{g} / \mathrm{mL}$ to the $\mathrm{MIC}_{90}$ of $4 \mu \mathrm{g} / \mathrm{mL}$.

However, if surgeons hydrate incisions and pressurize eyes with plain balanced salt solution (BSS), some of the vancomycin is washed out of the eye. ${ }^{27}$ In a recent series of ten of our cataract cases, these steps required an added volume $V_{\mathrm{a}}$ of $0.6-1.5 \mathrm{~mL}$ (mean: $1.05 \mathrm{~mL}$ ). The final concentration $C_{\mathrm{f}}$ of a diluted solution is $C_{\mathrm{f}}=C_{\mathrm{i}}\left(V_{\mathrm{i}} /\left[V_{\mathrm{i}}+V_{\mathrm{a}}\right]\right)$, where $V_{\mathrm{i}}$ is the initial volume $(0.54 \mathrm{~mL}$ for the anterior chamber of the pseudophakic eye) and $C_{\mathrm{i}}$ is the initial concentration. ${ }^{28}$ The concentration of vancomycin drops from $20 \mu \mathrm{g} / \mathrm{mL}$ to $5.2-9.7 \mu \mathrm{g} / \mathrm{mL}$ immediately after hydration and pressurization with plain BSS. After surgery, the concentration drops further, falling below the $\mathrm{MIC}_{90}$ of $4 \mu \mathrm{g} / \mathrm{mL}$ in 52 minutes to 181 minutes, which is probably insufficient for complete sterilization of the aqueous. ${ }^{15,20-25}$

Our analysis indicates that the choice of fluid used for incision hydration and eye pressurization is an important factor in the efficacy of endophthalmitis prophylaxis with vancomycin irrigation. If these steps are performed with the vancomycin/BSS irrigating solution, the vancomycin concentration is predicted to exceed the $\mathrm{MIC}_{90}$ for a sufficient time for effective endophthalmitis prophylaxis. However, if these steps are performed with plain BSS, the vancomycin concentration could decrease below the $\mathrm{MIC}_{90}$ before the effective kill time, and prophylaxis failures could occur. In early 2006, we switched from using BSS to using the vancomycin/BSS irrigating solution for incision hydration and eye pressurization, as recommended by others. ${ }^{15,29}$

\section{Methods}

This was a patient safety/quality improvement project. It was a prospective, interventional case series of all cataract operations in the Kaiser Permanente Colorado Ophthalmology Department from January 2002 to December 2014. Kaiser Permanente is a prepaid, community-based, health maintenance organization. Our Institutional Review Board reviewed the methods and waived the approval requirements, determining that this quality improvement project was not human subject research. 
Since 2002, all cataract surgeries in our department have been performed using vancomycin in the irrigating solution (BSS, Alcon, Fort Worth, TX, USA). Compounding is done at our in-house, licensed compounding pharmacies, which also compound our bevacizumab for intravitreal injection and systemic chemotherapy agents. In brief, vancomycin powder (Hospira, Inc, Lake Forest, IL, USA), is reconstituted per manufacturer instructions to $50 \mathrm{mg} / \mathrm{mL}$ with sterile water for injection in a laminar flow hood. It is then diluted 5:1 in normal saline and divided in a sterile manner into single-use syringes containing $10 \mathrm{mg}$ vancomycin $/ 1.0 \mathrm{~mL}$ normal saline. Each lot is tested for sterility by incubation for 14 days, using positive controls. Compounding costs for drug acquisition and technician salary and benefits are $<\$ 2.00$ per dose. The vancomycin mixture is injected by the circulating nurse into the $500 \mathrm{~mL}$ BSS bottle immediately before each surgical case, giving a final concentration of $20 \mu \mathrm{g} / \mathrm{mL} .{ }^{14}$ Most patients receive a preoperative cellulose pledget (Weck-Cel, Becton Dickinson, East Rutherford, NJ, USA) soaked with equal parts current-generation fluoroquinolone antibiotics, cyclopentolate $1 \%$, phenylephrine $10 \%$, and diclofenac $1 \%$ in the conjunctival cul-de-sac 45 minutes before surgery. ${ }^{29} \mathrm{In}$ the operating room, all patients receive povidone/iodine 5\% (Betadine, Alcon) preparation on the eyelid skin, eyelashes, and ocular surface before surgery. ${ }^{8}$

Throughout the study, at the end of surgery, all eyes were pressurized to a physiologic intraocular pressure, and incisions were hydrated. Each incision was carefully checked for aqueous leakage, either with a cellulose surgical spear or Seidel tested with fluorescein or Betadine solution. Leaky incisions were rehydrated or sutured. During the baseline period from 2002 to 2005 (baseline period), surgeons pressurized eyes and hydrated incisions with plain BSS. Starting in early 2006 (the intervention period), surgeons switched from using plain BSS to using the vancomycin/BSS irrigating solution for eye pressurization and incision hydration. We instructed the scrub technicians to draw up all syringes for these steps from the irrigating fluid. In our operating rooms, there are no syringes with plain BSS on the instrument table, eliminating the possibility of an incorrect syringe being passed to the surgeon.

Outpatient topical antibiotics were prescribed by every surgeon throughout the study. From 2002 to 2012, the majority of surgeons prescribed current-generation fluoroquinolones, while others prescribed tobramycin or neomycin/ polymyxin/dexamethasone. In late 2012 , we noted reports of increasing fluoroquinolone resistance by endophthalmitis isolates, ${ }^{18,30}$ but good coverage of Gram-positive eye infection isolates with trimethoprim. ${ }^{31}$ In early 2013, we uniformly switched outpatient antibiotics to polymyxin B/trimethoprim drops four times daily, starting the day before surgery and continuing for a week after surgery.

Our retinal surgeons reported endophthalmitis cases (pain, erythema, corneal edema, decreased vision, and panuveitis) to our Infection Control Department. Suspected endophthalmitis patients received vitreous and aqueous taps for cultures, as well as intravitreal antibiotic injections (vancomycin $1 \mathrm{mg} / 0.1 \mathrm{~mL}$ and ceftazidime $2.25 \mathrm{mg} / 0.1 \mathrm{~mL}$ or amikacin $400 \mu \mathrm{g} / 0.1 \mathrm{~mL}$ ). Patients with light perception or worse visual acuity typically underwent pars plana vitrectomy, per the Endophthalmitis Vitrectomy Study protocol. ${ }^{1}$

Starting in 2005, we queried our electronic health record (HealthConnect, Epic, Madison, WI, USA) to ascertain every case of endophthalmitis (International Classification of Diseases, Ninth Edition, ICD-9, 360.0×), regardless of cause. Both authors reviewed each case of endophthalmitis, and those occurring within 6 weeks of surgery, in the operated eye, without other intraocular procedures, trauma, or pathology, were classified as acute postcataract endophthalmitis. The presence or absence of intraoperative complications, including posterior capsule tear and vitreous loss, were recorded by surgeons in the electronic record for every case, as was the lens implant manufacturer, model, and power. Each chart was electronically audited for completeness, and surgeons were contacted to complete any missing data.

Odds ratios (ORs), confidence intervals (CIs), and $\chi^{2}$ tests for statistical significance $(P<0.05)$ were computed from standard formulas, ${ }^{32}$ using Microsoft Excel 2013 (Redmond, WA, USA). We estimated the confounding effects of our changing incidence of three risk factors for endophthalmitis: communication with the vitreous (posterior capsule tear and/ or vitreous loss) ${ }^{6}$ surgeon caseload, ${ }^{2}$ and the use of silicone IOLs. ${ }^{6}$ We multiplied the published ORs for endophthalmitis (approximately equal to relative risk [RR] for rare events in large samples), ${ }^{32}$ for each risk factor by the change in incidence of the risk factor, to develop weighted ORs. We multiplied the three weighted ORs to estimate the reduction in endophthalmitis due to risk factor modification. Then we estimated the effect of the intervention, without the confounding risk factor modifications, by dividing the raw ORs by the OR estimated for risk factor modification.

\section{Results}

From 2002 to 2014, 24 surgeons operated on 57,263 cataracts at seven surgical venues. The rate of posterior capsule 
rupture declined from $1.9 \%$ to $0.9 \%$, surgeons' cataract caseload increased by a factor of 2.67 , and the use of silicone IOLs decreased from approximately $60 \%$ to $2 \%$. Six cases of postcataract endophthalmitis occurred (Figure 1). Table 1 gives the details of the cases. One case of postcataract endophthalmitis was reported in 2003, with limited details. One case of chronic uveitis, operated in 2003, which resolved after pars plana vitrectomy, lensectomy, and removal of capsule plaques, and which grew Propionibacterium acnes in 2005, was classified as chronic postcataract endophthalmitis. Three of six cases occurred after operations complicated by posterior capsule tear and/or vitreous loss.

Table 2 summarizes the rates and statistics. From 2002 to 2005 (baseline), there were five cases of postcataract endophthalmitis after 12,400 cataract operations. From 2006 through 2014 (intervention), we experienced one case of endophthalmitis after 44,863 cataract operations. The rate of postcataract endophthalmitis was significantly higher in the baseline period $(0.40 / 1,000)$ than in the intervention period $(0.022 / 1,000)$ (raw OR: 18.1, 95\% CI: 2.11-154.9; $\left.\chi^{2}=13.5, P=0.00024\right)$. Since 2009 , we have experienced no cases of endophthalmitis after 32,753 cataract operations. After switching from majority use of fourth-generation fluoroquinolone outpatient antibiotics to uniform use of polymyxin $\mathrm{B} /$ trimethoprim in early 2013 , we continued to have no postcataract endophthalmitis for the following 13,205 cases.

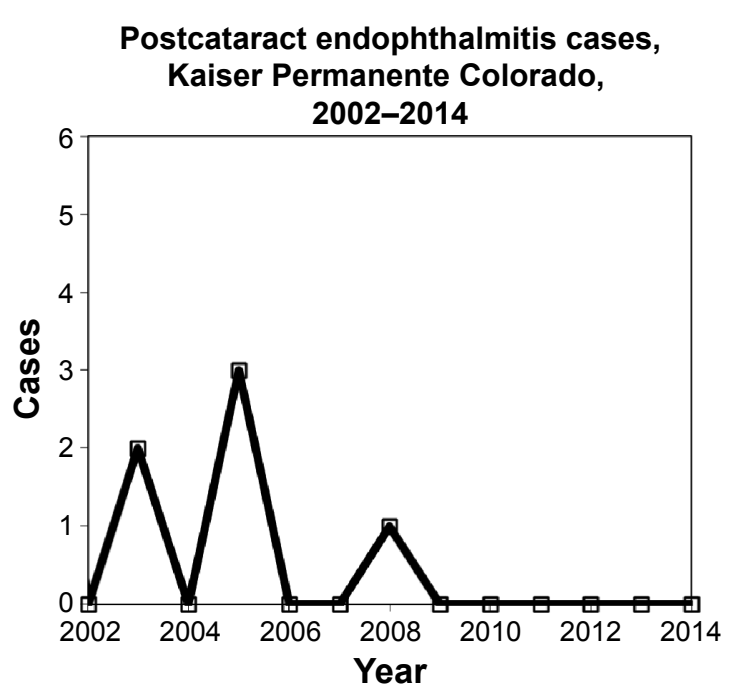

Figure I Endophthalmitis cases during the study period.

Notes: Starting in early 2006, surgeons switched from BSS to the vancomycin/ BSS irrigation fluid for incision hydration and eye pressurization, while maintaining the standard infection control practices of fluoroquinolone-soaked topical pledgets, povidone-iodine antisepsis of the eyelids and ocular surface, and vancomycin irrigation. Abbreviation: BSS, balanced salt solution.
Table 3 summarizes the estimated effects of the following known confounders: decreasing use of silicone IOLs, decreasing communication with the vitreous, and increasing surgeon caseload. The confounders are estimated to reduce the endophthalmitis rate by a factor of 2.05 , in total. Accounting for the confounders, the estimated effect of the intervention remained significant (adjusted OR: 8.78, 95\% CI: $\left.1.73-44.5 ; \chi^{2}=10.06, P=0.0015\right)$.

\section{Discussion}

We experienced a significant reduction in postcataract endophthalmitis after we switched from plain BSS to the vancomycin/BSS irrigation fluid for eye pressurization and incision hydration, while maintaining our standard infection control practices. This may be the first study to show a statistically significant decrease in postcataract endophthalmitis with vancomycin irrigation. ${ }^{14,27,33}$ Our experience of absence of endophthalmitis after 32,753 cataract operations from 2009 through 2014 is, to our knowledge, the longest, largest, multisurgeon, multivenue series of its kind.

The pharmacokinetic analysis indicates that switching from plain BSS to vancomycin/BSS for irrigation, pressurization, and incision hydration maintains the vancomycin concentration greater than the $\mathrm{MIC}_{90}$ for $>6$ hours. This switch may be necessary for effective endophthalmitis prophylaxis using vancomycin irrigation. ${ }^{20,21,25}$ Other authors draw opposite conclusions about the sufficiency of the vancomycin dwell time, based on the rate of aqueous turnover. ${ }^{34}$ But our calculations are based on published measurements of vancomycin concentrations versus time in postoperative cataract patients, ${ }^{15,22,26}$ as well as published kill times for Staphylococci, ${ }^{20,21,26}$ enhancing their validity. Experimental studies failing to show sterilization of aqueous after exposure to vancomycin for 30 minutes to 120 minutes $^{15,22-24}$ probably suffered from inadequate time for vancomycin to kill pathogens. $^{20,21,25}$ Other studies failing to show a significant decrease in postcataract endophthalmitis with vancomycin irrigation ${ }^{27,33}$ probably suffered from flaws in technique: hydrating incisions and pressurizing eyes with plain BSS instead of the vancomycin/BSS irrigating solution. ${ }^{27}$

Our study has additional strengths, which enhance the accuracy of discernment of endophthalmitis cases. Using an electronic health record probably reduced recall bias, because all cases of endophthalmitis were reviewed, regardless of cause. Mandatory surgeon reporting of the presence or absence of complications on every case also probably decreased recall bias. Our health system is a prepaid, closed 
Table I Details of endophthalmitis cases

\begin{tabular}{lllll}
\hline Case & Year & Intraoperative complications & Culture results & Outcome \\
\hline $\mathrm{I}$ & 2003 & None & Staphylococcus epidermidis & $*$ \\
2 & 2003 & None & Propionibacterium acnes & $20 / 30$ \\
3 & 2005 & PC tear, vitreous prolapse & $\alpha$-Hemolytic Streptococcus & $20 / 200$ \\
4 & 2005 & PC tear & Staphylococcus non-aureus & $20 / 25$ \\
5 & 2005 & None & $\alpha$-Hemolytic Streptococcus viridans & $20 / 400$ \\
6 & 2008 & PC tear, anterior vitrectomy, & Negative & $20 / 40$ \\
& & ECCE, ACIOL, wound leak & & \\
\hline
\end{tabular}

Notes: Case 2, operated in 2003, developed chronic uveitis, for which pars plana vitrectomy and capsulectomy were performed in 2005 , with culture results as shown. *Final visual acuity not available.

Abbreviations: $\mathrm{PC}$, posterior capsule; $\mathrm{AClOL}$, anterior chamber intraocular lens; ECCE, unplanned manual extracapsular cataract extraction.

network, so it is unlikely that patients would obtain care for endophthalmitis outside our network, without outside providers filing claims with diagnoses for reimbursement. This is expected to reduce ascertainment bias.

Injecting compounded vancomycin, typically $1 \mathrm{mg} / 0.1 \mathrm{~mL}$, directly into the anterior chamber at the end of surgery would give a sufficient concentration to kill nearly all Gram-positive endophthalmitis pathogens. ${ }^{12,27,29,33}$ The high initial concentration provides an extended time above the $\mathrm{MIC}_{90}{ }^{26}$ potentially sterilizing late contamination from wound leaks, blunting an important risk factor for endophthalmitis. ${ }^{7}$ But in agreement with US and European surgeons, ${ }^{35,36}$ the majority of surgeons in our Department have been reluctant to inject compounded intracameral antibiotics, citing the possibilities of concentration errors, ${ }^{37-40}$ pathogenic contamination, ${ }^{41}$ and toxic anterior segment syndrome. ${ }^{42-44}$ Mixing compounded vancomycin into the BSS bottle dilutes its concentration (and any contaminants, toxins, and formulation errors) 500:1, potentially minimizing risk compared to direct injections. For example, contamination with $10,000 \mathrm{CFU} / \mathrm{mL}$ of pathogens in the compounded vancomycin would be diluted 500:1 in the irrigating bottle, to $20 \mathrm{CFU} / \mathrm{mL}$ (the lower end of normal intraoperative contamination). ${ }^{15}$ An osmolarity error of $100 \mathrm{mOsm} / \mathrm{mL}$ would be diluted 500:1 in the irrigating bottle to nearly physiologic $300.6 \mathrm{mOsm} / \mathrm{mL}$. A five-fold concentration in mixing error, eg, by omitting the second dilution step, ${ }^{37,40}$ giving a concentration of $50 \mathrm{mg} / \mathrm{mL}$, would be diluted 500:1 in the irrigating bottle, to $100 \mu \mathrm{g} / \mathrm{mL}$. However, both this and higher concentrations have proven safe in thousands of operations. ${ }^{12,27,29}$ Errors of $\mathrm{pH}$ in compounding, or contamination with detergents or bacterial toxins, which are risk factors for toxic anterior segment syndrome, ${ }^{42-44}$ would be diluted 500:1 in the irrigating bottle, reducing the risk. We strongly believe that intracameral antibiotics should be prepared in a licensed, inspected compounding pharmacy, rather than by the staff of the operating room. However, surgeons at centers without access to such compounding pharmacies may wish to consider vancomycin irrigation over direct injection of compounded drugs for these safety reasons.

Vancomycin offers additional significant efficacy and safety advantages relative to other intracameral antibiotics. Gram-positive endophthalmitis pathogens have not developed resistance to vancomycin, ${ }^{16-19}$ although they have developed resistance to moxifloxacin ${ }^{18,30}$ and cefuroxime..$^{10,19}$ Recent reports of life-threatening anaphylaxis with intracameral cefuroxime are concerning. ${ }^{45,46}$ Some centers using intracameral cefuroxime are forced to perform skin prick testing, change antibiotics, or pretreat patients having betalactam allergies with antihistamines. ${ }^{47} \mathrm{We}$ are unaware of such severe side effects with intracameral vancomycin. We use vancomycin irrigation, pressurization, and hydration in every cataract patient and do not pretreat any patients with antihistamines. In agreement with others' results, ${ }^{48}$

Table 2 Cataract cases and endophthalmitis rates for the periods 2002-2005 and 2006-20I4

\begin{tabular}{|c|c|c|c|c|c|c|c|}
\hline Period & Cataract cases & PCE cases & Rate/I,000 & Odds ratio & $95 \% \mathrm{Cl}$ & $\chi^{2}$ & $P$ \\
\hline $2002-2005$ & 12,400 & 5 & 0.4 & 18.1 & $2.11-154.9$ & 13.5 & 0.00024 \\
\hline $2006-2014$ & 44,863 & $\mathrm{I}$ & 0.022 & & & & \\
\hline
\end{tabular}

Notes: Baseline, 2002-2005: preoperative pledget soaked with current-generation fluoroquinolone drops, povidone-iodine skin and ocular surface preparation, vancomycin $20 \mu \mathrm{g} / \mathrm{mL}$ irrigation, incision hydration, and eye pressurization with BSS; and intervention, 2006-20I4: switch from BSS to the vancomycin/BSS irrigation fluid for incision hydration and eye pressurization, while maintaining the baseline prophylactic measures. Statistics compare the baseline period to the intervention period.

Abbreviations: BSS, balanced salt solution; $\mathrm{Cl}$, confidence interval; PCE, postcataract endophthalmitis. 
Table 3 Estimated endophthalmitis risk reductions due to confounding variables

\begin{tabular}{lllllll}
\hline Risk factor & OR (RR) & Reference & $\begin{array}{l}\text { Prevalence } \\
\text { (background) }\end{array}$ & $\begin{array}{l}\text { Prevalence } \\
\text { (intervention) }\end{array}$ & $\begin{array}{l}\text { Risk factor } \\
\text { reduction }\end{array}$ & $\begin{array}{l}\text { Estimated PCE } \\
\text { rate reduction }\end{array}$ \\
\hline Silicone IOL use & 3.0 & 6 & $0.6(60 \%)$ & $0.02(2 \%)$ & $0.58(58 \%)$ & 1.74 \\
CWV & 6.5 & 6 & $0.019(1.9 \%)$ & $0.009(0.9 \%)$ & $0.010(1 \%)$ & 1.065 \\
Low surgical caseload & 1.27 (per 225 cases) & 2 & 221 cases & 309 cases & 88 cases & 1.106 \\
(below 350) & & & & & & 2.05 \\
Total & & & & & &
\end{tabular}

Notes: Low surgical caseload refers to a I.27-fold increase in relative risk of endophthalmitis for lower-volume surgeons (range: $5 \mathrm{I}-200$ cases/year, mean: 125 cases), to higher-volume surgeons (range: $20 \mathrm{I}-500$ cases/year, mean: 350 cases).

Abbreviations: OR, odds ratio; RR, relative risk; PCE, postcataract endophtalmitis; IOL, intraocular lens; CWV, communication with vitreous (posterior capsule tear and/or vitreous loss).

we have not noted an increase in cystoid macular edema with vancomycin irrigation, although it was noted in a teaching hospital with prolonged cases. ${ }^{49}$

Three percent to $8 \%$ of endophthalmitis cases are caused by Gram-negative bacteria, ${ }^{16,17}$ but we have never experienced a case of Gram-negative postcataract endophthalmitis. We hypothesize that povidone-iodine antisepsis, the fluoroquinolone-soaked topical pledgets, and topical antibiotic drops have been sufficient to eliminate Gram-negative bacteria in our center. Gram-negative endophthalmitis isolates have not developed resistance to fluoroquinolones or trimethoprim-sulfamethoxazole. ${ }^{17}$

The American Academy of Ophthalmology and the Centers for Disease Control and Prevention have urged caution in using vancomycin irrigation in the hospital setting, citing the possibility of inducing vancomycin resistance. ${ }^{50}$ However, fears of inducing vancomycin resistance in the population from use during outpatient eye surgery may be unfounded. ${ }^{25,51}$ With irrigation, if the $10 \mu \mathrm{g}$ dose of vancomycin in the anterior chamber were absorbed systemically, the serum concentration would be $10 \mu \mathrm{g} / 3,500 \mathrm{~mL}$ or $2.9 \mathrm{ng} / \mathrm{mL}$. With an intracameral injection of $1 \mathrm{mg}$, the serum vancomycin concentration would be $290 \mathrm{ng} / \mathrm{mL}$. These concentrations are almost certainly insufficient to induce systemic resistance. ${ }^{52}$ Measurements of antimicrobial susceptibilities of viridans group Streptococci isolated from the conjunctiva, nasopharynx, and oropharynx of patients did not show resistance to vancomycin after cataract surgery with vancomycin irrigation. ${ }^{53}$ Finally, some argue that prophylaxis should use a drug with a different mechanism of action than the drug used for treatment, to avoid treatment failures if endophthalmitis cases occur. ${ }^{34}$ However, if vancomycin prophylaxis essentially eradicates postcataract endophthalmitis (one case after 44,863 operations in our intervention period), the effect of a hypothetical treatment failure with vancomycin in a case of endophthalmitis becomes statistically small.

Some question the financial value of intracameral antibiotics. $^{34,43}$ However, a detailed cost-benefit study showed an 18-fold greater value of intracameral cefuroxime prophylaxis versus that with topical fourth-generation fluoroquinolone antibiotics. ${ }^{54}$ Our internal compounding pharmacy's cost of $<\$ 2.00$ per dose for vancomycin drug acquisition and pharmacy technician salary and benefits, as well as the retail price of compounded vancomycin (Leiter's Pharmacy, San Jose, CA, USA), compare favorably with the average acquisition price of $\$ 102.81-\$ 124.84$ for topical fourth-generation fluoroquinolones. ${ }^{55}$

A randomized clinical trial with thousands of patients, such as the European Society of Cataract and Refractive Surgeons endophthalmitis trial, ${ }^{9}$ would be the most definitive tool to determine whether irrigation, pressurization, and hydration with the vancomycin/BSS irrigating fluid significantly reduces postcataract endophthalmitis. However, such a study was far beyond the scope of this quality improvement project. Compared to a randomized clinical trial, any patient safety/ quality improvement project such as this interventional case series is inherently limited by the lack of a control group and the effects of confounding variables. Our decreasing posterior capsule rupture and vitreous loss rates, ${ }^{6,10}$ our increasing surgical volume, ${ }^{2,5}$ and our switch from silicone to acrylic lens implants ${ }^{6,9,21}$ probably contributed to our drop in the endophthalmitis rate.

We performed a sensitivity analysis to quantify the effects of these confounders. Table 3 summarizes these effects. A recent meta-analysis of over six million cataract cases quantified the RR and ORs of several risk factors. ${ }^{6}$ Posterior capsule tear/vitreous loss is associated with a 6.5 -fold increase in endophthalmitis. ${ }^{6}$ Our $1.0 \%$ reduction in capsule tears and/or vitreous loss, from $1.9 \%$ to $0.9 \%$ of cases, would be expected to reduce our endophthalmitis rate by a factor of $1+(6.5 \times 0.01)=1.065$. Silicone IOLs are associated with a 3.0-fold increased risk for endophthalmitis versus polymethyl methacrylate or acrylic lenses. ${ }^{6}$ Our 58\% reduction in the use of silicone lenses, from $60 \%$ of cases to $2 \%$ of cases, would be expected to reduce our endophthalmitis rate by 
a factor of $3.0 \times 0.58=1.74$. Low annual surgical caseload has been associated with an increasing endophthalmitis rate, with an RR of 1.27 per 225 cases. $^{2}$ Our mean surgical volume increased by 88 cases, from 221 in the baseline period to 309 in the intervention period. This would be expected to reduce our endophthalmitis rate by a factor of $1+$ $(0.27 \times[88 / 225])=1.106$. Some confounders are correlated: compared to surgeons with low annual caseloads, surgeons with high caseloads have lower capsule tear rates ${ }^{56}$ and they use intracameral antibiotics more frequently. ${ }^{13}$ Nonetheless, we multiplied the effects of the three expected confounders, to give their maximum, total estimated effect on our endophthalmitis rate: $1.74 \times 1.065 \times 1.106=2.05$. We might expect as much as a 2.05 -fold reduction in endophthalmitis due to these confounders. Clearly, these confounders cannot explain the 18-fold decrease in the endophthalmitis rate we observed. After accounting for the estimated effect of the three confounders, the estimated adjusted effect of the intervention remained statistically significant.

Future research could further enhance our understanding of postcataract endophthalmitis. National endophthalmitis registries, as in Sweden ${ }^{10}$ and Taiwan, ${ }^{5}$ indicate trends in rates, with large enough sample sizes to ensure statistical and clinical significance. Annual reporting of the US Medicare endophthalmitis rate would help American surgeons compare their rates to international rates and trends. Large health care systems, such as Kaiser Permanente ${ }^{11}$ and the United States Veterans Administration, ${ }^{57}$ could establish uniform standards for prophylaxis and monitor known risk factors such as posterior capsule rupture and IOL type. Then, they could report endophthalmitis rates as interventions are made, providing prospective evidence for their efficacy. Studies showing resistance rates of endophthalmitis pathogens should give the $\mathrm{MIC}_{90}$ values, ${ }^{18,19}$ together with percentage resistance, ${ }^{16,17,30}$ because topical and intracameral antibiotics attain much higher concentrations than the break points for systemic antibiotics. ${ }^{31}$ When intracameral antibiotics are used, the added risk reduction due to topical antibiotics is probably small. ${ }^{9-11}$ Because US surgeons commonly use fourth-generation fluoroquinolones for topical endophthalmitis prophylaxis, ${ }^{13}$ emerging resistance to these agents should continue to be monitored. ${ }^{18,30}$ Surgeons concerned about emerging fluoroquinolone resistance may choose to switch to more effective, older-generation antibiotics, such as trimethoprim-polymyxin $\mathrm{B},{ }^{31}$ as we did.

In summary, we experienced a significant reduction in postcataract endophthalmitis when we switched from plain BSS to the vancomycin/BSS irrigating solution for hydrating incisions and pressurizing eyes, while maintaining our standard prophylactic measures of betadine antisepsis of the eyelids and ocular surface, antibiotic-soaked pledgets, topical outpatient antibiotics, and vancomycin irrigation. The pharmacokinetics profile indicates that the switch in fluids for hydration and irrigation was necessary for effective endophthalmitis prophylaxis with vancomycin irrigation. Diluting compounded vancomycin in the irrigating bottle may offer significant safety advantages relative to direct intracameral injection of compounded drugs. Switching from majority use of fourth-generation fluoroquinolone outpatient topical antibiotics to uniform use of polymyxin B/trimethoprim was not associated with any cases of endophthalmitis. Cataract surgeons who irrigate with vancomycin should consider hydrating incisions and pressurizing eyes with the irrigating solution, instead of plain BSS.

\section{Acknowledgments}

The authors thank Robin L Meinberg, Department of Infection Control, Kaiser Permanente Colorado Region, for her expert data collection. Salary support for the individuals performing this project (including design and conduct of the study; collection, management, analysis, and interpretation of the data; and preparation, review, and approval of the manuscript) was provided by the Colorado Permanente Medical Group and the Kaiser Permanente Colorado Region. This work was presented in part at the European Ophthalmology Society Annual Meeting, Copenhagen, Denmark, June 2013.

\section{Author contributions}

LPS reviewed literature, developed intervention protocols, reviewed the data, performed data analysis, drafted the manuscript and edited the final copy. MAS performed investigation of cases before baseline, developed intervention protocols, trained staff in interventions, extracted and reviewed data, edited the draft manuscript, and approved the final copy.

Based on these contributions, both authors comply with the guidelines for authorship.

\section{Disclosure}

The authors report no conflicts of interest in this work.

\section{References}

1. Endophthalmitis Vitrectomy Study Group. Results of the endophthalmitis vitrectomy study. Arch Ophthalmol. 1995;113(12):1479-1496.

2. Keay L, Gower EW, Cassard SD, Tielsch JM, Schein OD. Postcataract surgery endophthalmitis in the United States: analysis of the complete 2003 to 2004 Medicare database of cataract surgeries. Ophthalmology. 2012 119(5):914-922. 
3. Gollogly HE, Hodge DO, St Sauver JL, Erie JC. Increasing incidence of cataract surgery: population-based study. J Cataract Refract Surg. 2013;39(9):1383-1389.

4. United States Census Department. US and World Population Clock; 2015. Available from: www.census.gov/popclock. Accessed January 16, 2015.

5. Fang YT, Chien LN, Ng YY, et al. Association of hospital and surgeon operation volume with the incidence of postoperative endophthalmitis: Taiwan experience. Eye (Lond). 2006;20(8):900-907.

6. Cao H, Zhang L, Li L, Lo S. Risk factors for acute endophthalmitis following cataract surgery: a systematic review and meta-analysis. $P L o S$ One. 2013;8(8):e71731.

7. Wallin T, Parker J, Jin Y, Kefalopoulos G, Olson RJ. Cohort study of 27 cases of endophthalmitis at a single institution. J Cataract Refract Surg. 2005;31(4):735-741.

8. Speaker MG, Menikoff JA. Prophylaxis of endophthalmitis with topical povidone-iodine. Ophthalmology. 1991;98(12):1769-1775.

9. ESCRS Endophthalmitis Study Group. Prophylaxis of postoperative endophthalmitis following cataract surgery: results of the ESCRS multicenter study and identification of risk factors. $J$ Cataract Refract Surg. 2007;33(6):978-988.

10. Friling E, Lundstrom M, Stenevi U, Montan P. Six-year incidence of endophthalmitis after cataract surgery: Swedish national study. $J$ Cataract Refract Surg. 2013;39(1):15-21.

11. Shorstein NH, Winthrop KL, Herrinton LJ. Decreased postoperative endophthalmitis rate after institution of intracameral antibiotics in a Northern California eye department. J Cataract Refract Surg. 2013; 39(1):8-14.

12. Anijeet $\mathrm{D}$, Palimar P, Peckar C. Intracameral vancomycin following cataract surgery: an eleven-year study. Clin Ophthalmol. 2010;4: 321-326.

13. Leaming D. Results of the 2012 ASCRS Cataract Surgery Survey; 2015. Available from: www.analeyz.com/NEWAnaleyz $\% 20$ ASCRS $\% 20$ 2012.htm. Accessed February 6, 2015.

14. Gills JP. Filters and antibiotics in irrigating solution for cataract surgery (Letter). J Cataract Refract Surg. 1991;17(5):385.

15. Soto AM, Mendivil MP. The effect of topical povidone-iodine, intraocular vancomycin, or both on aqueous humor cultures at the time of cataract surgery. Am J Ophthalmol. 2001;131(3):293-300.

16. Han DP, Wisniewski SR, Wilson LA, et al; Endophthalmitis Vitrectomy Study Group. Spectrum and susceptibilities of microbiologic isolates in the endophthalmitis vitrectomy study. Am J Ophthalmol. 1996; 122(1):1-17.

17. Recchia FM, Busbee BG, Pearlman RB, Carvalho-Recchia CA, Ho AH. Changing trends in the microbiologic aspects of postcataract endophthalmitis. Arch Ophthalmol. 2005;123(3):341-346.

18. Harper T, Miller D, Flynn HW Jr. In vitro efficacy and pharmacodynamic indices for antibiotics against coagulase-negative Staphylococcus endophthalmitis isolates. Ophthalmology. 2007;114(5):871-875.

19. Seal D, Reischl U, Behr A, et al; ESCRS Endophthalmitis Study Group. ESCRS Endophthalmitis Study Group. Laboratory diagnosis of endophthalmitis: comparison of microbiology and molecular methods in the European Society of Cataract and Refractive Surgeons multicenter study and susceptibility testing. J Cataract Refract Surg. 2008; 34(9):1439-1450.

20. Lowdin E, Odenholt I, Cars O. In vitro studies of pharmacodynamic properties of vancomycin against Staphylococcus aureus and Staphylococcus epidermidis. Antimicrob Agents Chemother. 1998;42(10): 2739-2744.

21. Kodjikian L, Renaud FN, Roques C, et al. In vitro influence of vancomycin on adhesion of a Staphylococcus epidermidis strain encoding intercellular adhesion locus ica to intraocular lenses. J Cataract Refract Surg. 2005;31(5):1050-1058.

22. Ferro JF, de Pablos M, Logrono MJ, Guisasola L, Aizpuru F. Postoperative contamination after using vancomycin and gentamicin during phacoemulsification. Arch Ophthalmol. 1997;115(2):165-170.
23. Feys J, Salvanet-Bouccara A, Emond JP, Dublanchet A. Vancomycin prophylaxis and intraocular contamination during intraocular surgery. J Cataract Refract Surg. 1997;23(8):894-897.

24. Gritz DC, Cevallos AV, Smolin G, Whitcher JP. Intraocular supplementation of intraocular irrigating solutions: an in vitro model of antibacterial action. Ophthalmology. 1996;103(8):1204-1209.

25. Libre PE, Della-Latta P, Chin NX. Intracameral antibiotic agents for endophthalmitis prophylaxis: a pharmacokinetic model. $J$ Cataract Refract Surg. 2003;29(9):1791-1794.

26. Murphy CC, Nicholson S, Quah SA, Batterbury M, Neal T, Kaye SB. Pharmacokinetics of vancomycin following intracameral bolus injection in patients undergoing phacoemulsification cataract surgery. $\mathrm{Br}$ J Ophthalmol. 2007;91(10):1350-1353.

27. Gimbel HV. The Case for Intracameral Vancomycin. Cataract and Refractive Surgery Today. 2005:73-75. Available from: http://crstoday. com/2005/02/0205_F9_Gimbel.html/. Accessed February 6, 2015.

28. Lehmann O, Thompson JJ, White LO, Keys MF, Campbell MJ. Halflife of intracameral gentamicin after phacoemulsification. $J$ Cataract Refract Surg. 1997;23(6):883-888.

29. Gills JP. Consultation section. J Cataract Refract Surg. 2004;30(8): 1616-1617.

30. Schimel AM, Miller D, Flynn HW Jr. Evolving fluoroquinolone resistance among coagulase-negative Staphylococcus isolates causing endophthalmitis. Arch Ophthalmol. 2012;130(12):1617.

31. Asbell PA, Colby KA, Deng S, et al. Ocular TRUST: nationwide antimicrobial susceptibility patterns in ocular isolates. Am J Ophthalmol. 2008;145(6):951-958.

32. Bland JM, Altman DG. Statistics notes: the odds ratio. BMJ. 2000; 320(7247): 1468 .

33. Arshinoff SA, Bastianelli PA. Incidence of postoperative endophthalmitis after immediate sequential bilateral cataract surgery. $J$ Cataract Refract Surg. 2011;37(12):2105-2114.

34. Schimel AM, Alfonso EC, Flynn HW Jr. Endophthalmitis prophylaxis for cataract surgery: are intracameral antibiotics necessary? JAMA Ophthalmol. 2014;132(11):1269-1270.

35. Chang DF, Braga-Mele R, Mamalis N. ASCRS Cataract Clinical Committee. Prophylaxis of postoperative endophthalmitis after cataract surgery: results of the 2007 ASCRS member survey. J Cataract Refract Surg. 2007;33:1801-1805.

36. Barry P. Adoption of intracameral antibiotic prophylaxis of endophthalmitis following cataract surgery. J Cataract Refract Surg. 2014; 40(1):138-142.

37. Olavi P. Ocular toxicity in cataract surgery because of inaccurate preparation and erroneous use of $50 \mathrm{mg} / \mathrm{mL}$ intracameral cefuroxime. Acta Ophthalmol. 2012;90(2):e153-e154.

38. Delyfer MN, Rougier MB, Leoni S, et al. Ocular toxicity after intracameral injection of very high doses of cefuroxime during cataract surgery. J Cataract Refract Surg. 2011;37(2):271-278.

39. Querishi F, Clark D. Macular infarction after inadvertent intracameral cefuroxime. J Cataract Refract Surg. 2011;37(6):1168-1169.

40. Fry L. Vancomycin dilution error (Letter). J Cataract Refract Surg. 2005;31(8):1674.

41. Goldberg RA, Flynn HW Jr, Miller D, Gonzalez S, Isom RF. Streptococcus endophthalmitis outbreak after intravitreal injection of bevacizumab: one-year outcomes and investigative results. Ophthalmology. 2013;120(7):1448-1453.

42. Mamalis N, Edelhauser HF, Dawson DG, Chew J, Le Boyer RM, Werner L. Toxic anterior segment syndrome. $J$ Cataract Refract Surg. 2006;32(2):324-333.

43. Liesegang TJ. Intracameral antibiotics: questions for the United States based on prospective studies. J Cataract Refract Surg. 2008;34(3): 505-509.

44. Braga-Mele R, Chang DF, Henderson BA, Mamalis N, Talley-Rostov A, Vasavada A. ASCRS Clinical Cataract Committee. Intracameral antibiotics: safety, efficacy, and preparation. $J$ Cataract Refract Surg. 2014;40(12):2134-2142. 
45. Villada JR, Vicente U, Javaloy J, Alió JL. Severe anaphylactic reaction after intracameral antibiotic administration during cataract surgery. J Cataract Refract Surg. 2005;31(3):620-621.

46. Moisseiev E, Levinger E. Anaphylactic reaction following intracameral cefuroxime injection during cataract surgery. J Cataract Refract Surg. 2013;39(9):1432-1434.

47. Montan P, Wejde G, Setterquist H, Rylander M, Zetterstrom C. Prophylactic intracameral cefuroxime: evaluation of safety and kinetics in cataract surgery. J Cataract Refract Surg. 2002;28(6):982-987.

48. Ball JL, Barrett GD. Prospective randomized controlled trial of the effect of intracameral vancomycin and gentamicin on macular retinal thickness and visual function following cataract surgery. $J$ Cataract Refract Surg. 2006;32(5):789-794.

49. Axer-Siegel R, Stiebel-Kalish H, Rosenblatt I, Strassmann E, Yassur Y, Weinberger D. Cystoid macular edema after cataract surgery with intraocular vancomycin. Ophthalmology. 1999;106(9):1660-1664.

50. Task Force AAO-CDC. The Prophylactic use of Vancomycin for Intraocular Surgery. Quality of Care Publications. Number 515. San Francisco, CA: American Academy of Ophthalmology; 1999

51. Gordon YJ. Vancomycin prophylaxis and emerging resistance: are ophthalmologists the villains? The heroes? Am J Ophthalmol. 2001; 131(3):371-376
52. Drlica K. The mutant selection window and antimicrobial resistance. J Antimicrob Chemother. 2003;52(1):11-17.

53. Seppala H, Al-Juhaish M, Jarvinen H, Laitinen R, Houvinen P. Effect of prophylactic antibiotics on antimicrobial resistance of viridans streptococci in the normal flora of cataract surgery patients. J Cataract Refract Surg. 2004;30(2):307-315.

54. Sharifi E, Porco TC, Naseri A. Cost-effectiveness analysis of intracameral cefuroxime use for prophylaxis of endophthalmitis after cataract surgery. Ophthalmology. 2009;116(10):1887-1896.

55. Massachusetts Executive Office of Health and Human Services. Mass Health Drug List, Table 34: Antibiotics: Ophthalmic; 2015. Available from: https://masshealthdruglist.ehs.state.ma.us/MHDL/pubtheradetail. do?id=34. Accessed January 24, 2015.

56. Habib M, Mandal K, Bunce CV, Fraser SG. The relation of volume with outcome in phacoemulsification surgery. Br J Ophthalmol. 2004; 88(5):643-646.

57. Greenberg PB, Tseng VL, Wu WC, et al. Prevalence and predictors of ocular complications associated with cataract surgery in United States veterans. Ophthalmology. 2011;118(3):507-514.
Clinical Ophthalmology

\section{Publish your work in this journal}

Clinical Ophthalmology is an international, peer-reviewed journal covering all subspecialties within ophthalmology. Key topics include: Optometry; Visual science; Pharmacology and drug therapy in eye diseases; Basic Sciences; Primary and Secondary eye care; Patien Safety and Quality of Care Improvements. This journal is indexed on

Submit your manuscript here: http://www.dovepress.com/clinical-ophthalmology-journal

\section{Dovepress}

PubMed Central and CAS, and is the official journal of The Society of Clinical Ophthalmology (SCO). The manuscript management system is completely online and includes a very quick and fair peer-review system, which is all easy to use. Visit http://www.dovepress.com/ testimonials.php to read real quotes from published authors. 